\title{
PEMBELAJARAN BAHASA INGGRIS MELALUI PERMAINAN TEBAK KATA DENGAN WEB CRAWLER MENGGUNAKAN ANDROID
}

\author{
Dwiki Jatikusumo $^{1}$, Rahmat Rian Hidayat ${ }^{2}$ \\ ${ }^{1,2}$ Program Studi Teknik Informatika, Fakultas Ilmu Komputer, Universitas Mercu Buana \\ Jl. Raya Meruya Selatan, Kembangan, Jakarta, 11650, Indonesia \\ E-mail: ${ }^{1}$ wwiki.jatikusumo@merubuana.ac.id, ${ }^{2}$ rahmat.rian@mercubuana.ac.id
}

\begin{abstract}
Abstrak
Bahasa Inggris merupakan bahasa internasional, dan jaman globalisasi sekarang, khususnya dalam sains dan teknologi. Dari renstra penelitian di Universitas Mercu Buana topik penelitian yang dibutuhkan merupakan terkait dengan aplikasi pembelajaran berbasis multimedia. Kemudian, khususnya pembelajaran Bahasa Inggris. Teknik yang dipakai menggunakan web crawler dikombinasikan dengan permainan tebak kata bahasa Inggris. Proses yang dilakukan adalah pengguna memilih kategori kosa kata yang akan dimainkan untuk tebak katanya, kemudian akan tampil susunan satu kata dari beberapa huruf tersebut untuk ditebak jawaban dari pertanyaan yang akan tampil. Target pencapaian jangka panjang riset ini adalah terciptanya sebuah aplikasi permainan tebak kata Bahasa Inggris yang interaktif terhadap siswa dan mahasiswa mulai dari tingkat Sekolah Dasar sampai Perguruan Tinggi.
\end{abstract}

Kata kunci-bahasa inggris, web crawler, word guess

\begin{abstract}
English is an international language, and the age of globalization now, especially in science and technology. Techniques used using web crawlers combined with an English word guess game. The process is done the user chooses the vocabulary categories to be played for guessing words, then will appear the composition of one word of some of the letters to guess the answer of the question that will appear. The long-term goal of this research is the creation of an interactive English word guessing app for students and students ranging from Elementary School to Higher Education.
\end{abstract}

Keywords—English, web crawler, word guess

\section{PENDAHULUAN}

Bahasa memainkan peran penting dalam kehidupan manusia. Satu berusaha untuk memperoleh, mempelajari dan menggunakan bahasa sebagai alat komunikasi, dan sekaligus sebagai simbol sosial kemanusiaan. Dengan menggunakan bahasa seseorang bisa membuat pernyataan, menyampaikan fakta dan pengetahuan, menjelaskan atau melaporkan sesuatu, dan menjaga hubungan sosial antara para pengguna bahasa. Hal ini menunjukkan bahwa dengan menggunakan bahasa, orang dapat mengekspresikan ide-ide mereka, perasaan, dan lain-lain.

Di negara berkembang seperti seperti Indonesia, Inggris memiliki peran vital dalam semua aspek kehidupan, khususnya dalam sains dan teknologi. Selain itu, dapat digunakan untuk mengembangkan hubungan dalam forum internasional, untuk membaca buku bahasa 
Inggris (terutama untuk siswa dari sekolah dasar sampai dengan perguruan tinggi), untuk mempererat hubungan antar bangsa-bangsa di dunia, dan lain-lain.

Menurut [1], metode kursus bahasa Inggris yang ada sekarang ini lahir, karena banyak orang yang memiliki kemampuan Bahasa Inggris rendah. Namun kursus tersebut memiliki kekurangan antara lain: biaya kursus yang tinggi, materi yang disampaikan monoton, waktu kursus yang tidak efisien, tentor atau pengajar kurang berkompeten, dan fasilitas pembelajaran Bahasa Inggris yang kurang memadai. Dalam riset ini, penulis mencoba teknik web crawler dikombinasikan dengan permainan tebak kata bahasa Inggris. Proses yang dilakukan adalah pengguna memilih kategori kosa kata yang akan dimainkan untuk tebak katanya, kemudian akan tampil susunan satu kata dari beberapa huruf tersebut untuk ditebak jawaban dari pertanyaan yang akan tampil.

Menurut [2], pembelajaran kooperatif mengembangkan keterampilan berpikir maupun keterampilan sosial siswa seperti, bekerja sama, setia kawan dan mengemukakan pendapat. Model pembelajaran kooperatif memiliki banyak ragam diantaranya model Student Team Achievement Division (STAD), Tebak Kata, Group Investigasi (GI), Team Game Tournament (TGT), dan masih banyak lagi.

Dari hasil penelitian [6], menggambarkan siswa lebih senang dan merasa santai dan nyaman jika kuliah yang diadakan berbasis online karena siswa menganggap tidak merasa jenuh dengan kondisi kelas yang tidak kondusif dan berbagai hal lain yang terjadi dikelas. Sehingga bisa diterapkan online ke aplikasi berbasis Android.

Tebak kata dapat dijadikan model alternatif untuk mendorong siswa aktif dan belajar bekerjasama dengan pasangannya [7].

Tebak kata bisa diterapkan sebagai salah satu media pembelajaran alternatif bagi guru untuk meningkatkan minat belajar peserta didik dengan menggunakan pendekatan permainan yang menyenangkan, menantang, seru dan menarik serta fokus [8].

Strategi menebak lebih disukai oleh siswa sebagai kosa kata mereka strategi belajar, itu tidak membantu dalam meningkatkan aktif pasif dan terkontrol pengetahuan kosa kata [9].

Menurut [10], dari beberapa teknik yang ada banyak strategi untuk belajar kosakata berdasarkan permainan dalam bahasa Inggris. Ada dua teknik baru tentang belajar kosa kata yaitu teka-teki silang, kata ajaib (wonder word puzzles), dan satu teknik semi-tradisional, tetapi diterima secara luas yaitu tebak kata. Oleh karena itu, dalam riset ini penulis menggunakan model tebak kata sebagai alat dalam pembelajaran Bahasa Inggris.

Dalam menerapkan model tebak kata ada beberapa hal yang harus disiapkan adalah sebagai berikut:

- Siapkan materi yang akan di sampaikan.

- Siapkan bahan ajar yang di butuhkan.

- Siapkan kata kunci yang akan di pertanyakan.

Menurut [3], web crawler atau biasa disebut juga Spiders dan robots merupakan aplikasi yang menggunakan Uniform Resource Locator atau URL sebagai acuan untuk mengunduh dengan link yang akan digunakan. Proses ini dilakukan untuk menyimpan data dari halaman web yang akan diambil datanya. Pada gambar 1 merupakan arsitektur umum untuk web crawler. HTTP (HyperText Transfer Protocol) sebagai protokol dari URL yang akan diakses untuk 
masuk ke World Wide Web atau WWW untuk disimpan ke dalam storage sebagai data yang sudah di filter melalui web crawler.

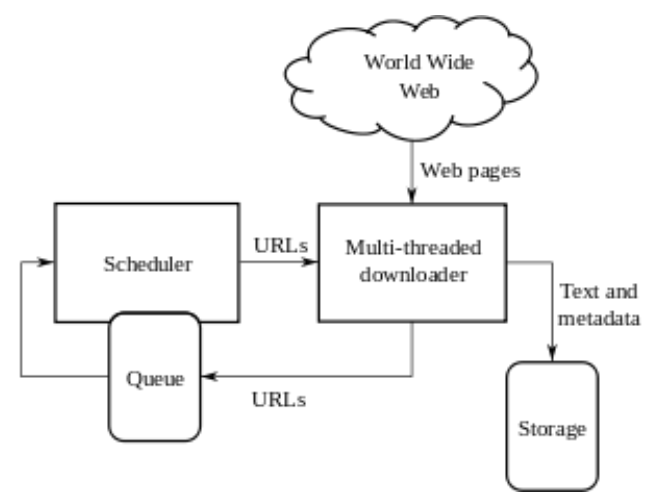

Gambar 1 Arsitektur umum web crawler [4]

\section{METODE PENELITIAN}

Metodologi riset berisi langkah-langkah yang akan digunakan dalam riset ini agar terstruktur dengan baik. Dengan sistematika ini proses riset dapat dipahami dan diikuti oleh pihak lain. Riset yang akan dilakukan adalah untuk merancang sistem yang diperoleh dari pengamatan data-data yang ada. Tahapan pengembangan yang digunakan penulis dalam riset ini yaitu menggunakan model MDLC (Mobile App Development Live Cycle).

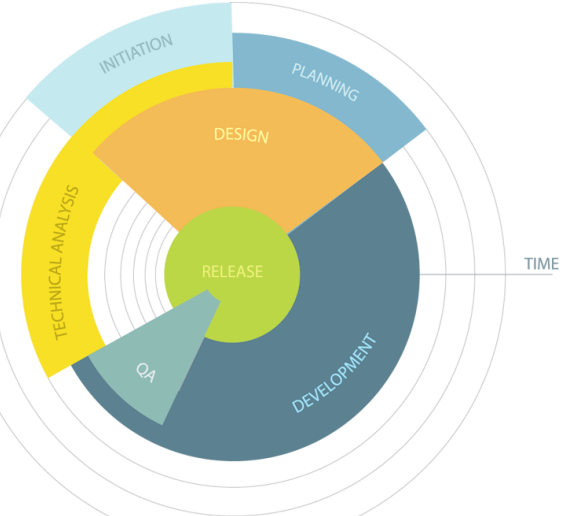

Gambar 2 Model MDLC [5]

\subsection{Inisiasi (initation)} didapat.

Pada tahap ini perencaan dimana penulis mencoba mencari solusi dari permasalahan yang

\subsection{Perencanaan (planning)}

Pada tahap perencanaan, kita berusaha mengenal setiap permasalahan yang muncul pada pengguna dengan mendekomposisi dan merealisasi use case diagram lebih lanjut, mengenai kompenen-kompenen sistem atau perangkat lunak, objek-objek, hubungan antar objek dan sebagainya.

\subsection{Analisis Teknis (technical analysis)}

Pada tahap pembuatan ini merupakan proses analisis sistem secara teknis sesuai dengan kebutuhan yang telah dianalisis sebelumnya. 


\subsection{Desain dan pengembangan (design and development)}

Untuk dapat dimengerti oleh mesin, dalam hal ini adalah smartphone, maka desain tadi harus diubah bentuknya menjadi bentuk yang dapat dimengerti oleh mesin, yaitu ke dalam bahasa pemrograman melalui proses coding.

\subsection{Quality Assurance}

Sesuatu yang dibuat diujicobakan. Demikian juga dengan software. Semua fungsi-fungsi software harus diujicobakan, agar software bebas dari error, dan hasilnya harus benar-benar sesuai dengan kebutuhan yang sudah didefinisikan sebelumnya.

\subsection{Rilis (release)}

Aplikasi dirilis ke umum, sebagai contoh ke Android (Play Store) dan iOS (App Store).

\section{HASIL DAN PEMBAHASAN}

\subsection{Arsitektur Aplikasi}

Dari arsitektur pada gambar 3, merupakan alur yang berjalan dalam aplikasi ini. Soal akan di random dari pengguna mencari dari kategori apa, misalkan buah. Kemudian, server akan mencari pertanyaan serta jawaban sesuai dengan permintaan dari pengguna di website kamus Bahasa Inggris yang sudah dikonfigurasi sebelumnya. Lalu, website kamus Bahasa Inggris akan dilakukan crawling data berupa pertanyaan dan jawaban yang akan disimpan di database server. Website tersebut menggunakan https://dictionary.cambridge.org. Kemudian, server akan mengirimkan data pertanyaan dan jawaban ke pengguna.

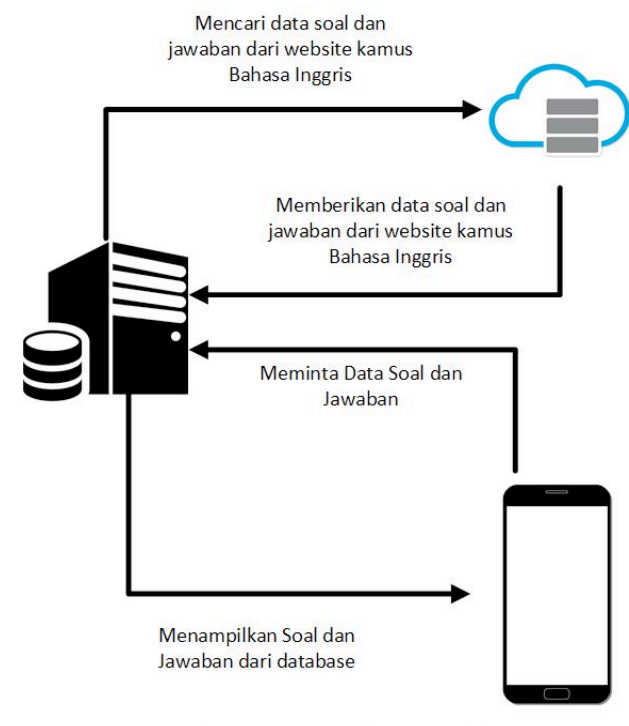

Gambar 3 Arsitektur aplikasi

\subsection{Pengujian Aplikasi}

\subsubsection{Pengguna mencoba halaman login dan registrasi}

Pada halaman ini pengguna dapat login, jika sebelumnya sudah mendaftar. Bagi yang belum mendaftar, maka dapat mendaftar di halaman registrasi. Berikut pengujiannya, untuk halaman login dan registrasi: 


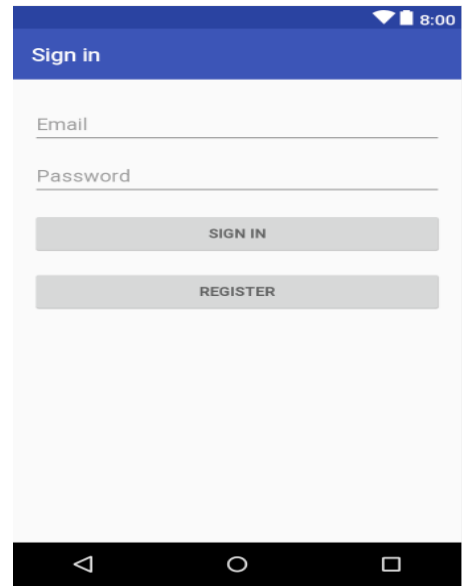

Gambar 4 Halaman login

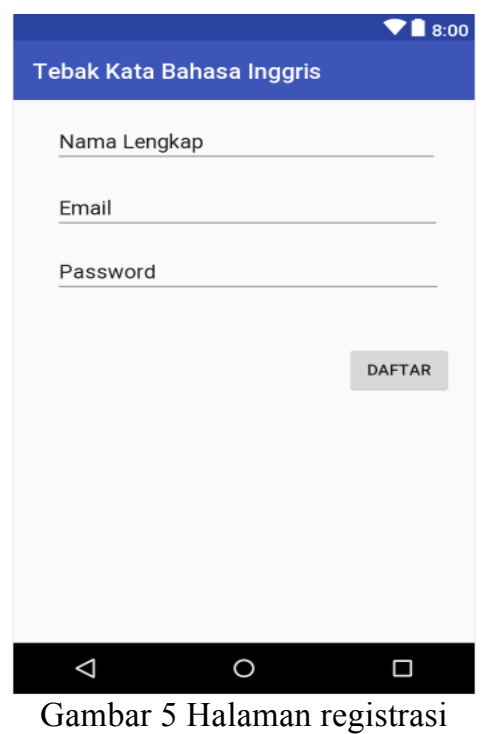

\subsubsection{Pengguna mencoba halaman pilih kategori}

Pada halaman ini, pengguna dapat memilih kategori yang akan menjadi bahan pertanyaan dan jawabannya. Berikut pengujiannya:

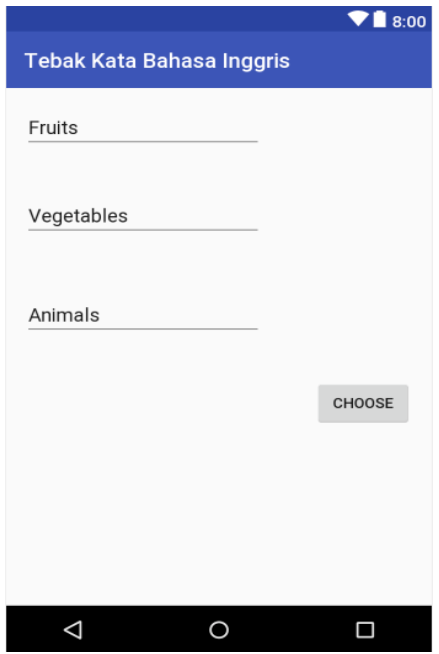

Gambar 6 Halaman skor akhir permainan 


\subsubsection{Pengguna mencoba halaman pilih jawaban}

Pada halaman ini, pengguna dapat menjawab pertanyaan dalam waktu 25 detik, dan bisa memberi bantuan dengan menekan tombol "hint" sebanyak dua kali. Kemudian dapat jika sudah bisa tekan tombol "answer". Berikut pengujiannya:

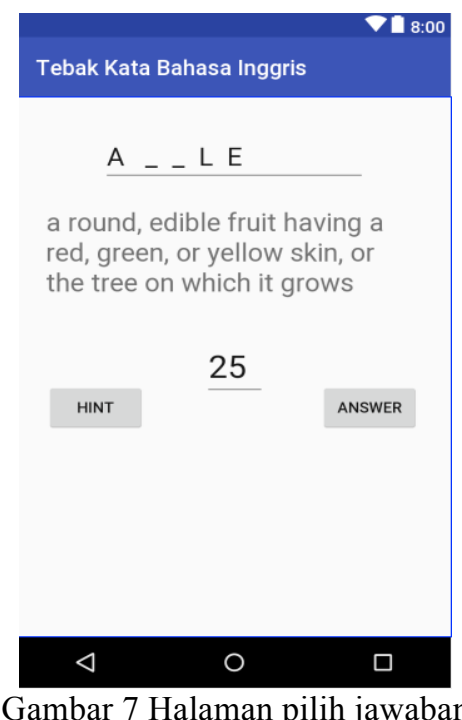

\subsubsection{Pengguna melihat skor akhir permainan}

Pada halaman ini, pengguna dapat melihat hasil akhir dari pertanyaan-pertanyaan yang sudah diberikan dengan 10 pertanyaan. Berikut pengujiannya:

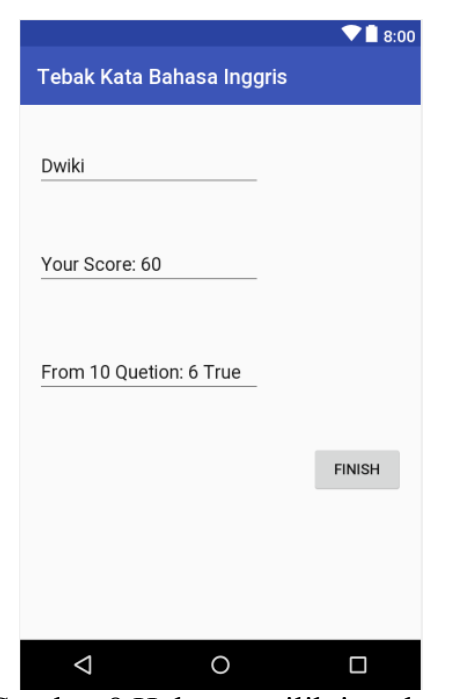

Gambar 8 Halaman pilih jawaban

\subsection{Pengujiaan Web crawler}

Pengujian ini menggunakan internet dalam melakukannya, karena diambil dari website https://dictionary.cambridge.org. Hasilnya tidak ada yang error dalam pengambilan data, yaitu $100 \%$. Berikut hasil dari ujicobanya. 
Tabel 1 Penarikan data dari website

\begin{tabular}{|c|l|c|c|}
\hline Nomor & \multicolumn{1}{|c|}{ Pertanyaan } & Jawaban & Persentase \\
\hline 1 & $\begin{array}{l}\text { a written text that can be } \\
\text { published in printed or electronic } \\
\text { form? }\end{array}$ & book & $100 \%$ \\
\hline 2 & $\begin{array}{l}\text { a round fruit with firm, white } \\
\text { flesh and a green, red, or yellow } \\
\text { skin? }\end{array}$ & apple & $100 \%$ \\
\hline 3 & $\begin{array}{l}\text { the yellow flesh and juice of) a } \\
\text { large tropical fruit with a rough } \\
\text { orange or brown skin and pointed } \\
\text { leaves on top? }\end{array}$ & $\begin{array}{l}\text { pineapple } \\
\text { a round sweet fruit that has a } \\
\text { thick orange skin and an orange } \\
\text { centre divided into many parts? }\end{array}$ & orange \\
\hline 5 & $\begin{array}{l}\text { a small, round, purple or pale } \\
\text { green fruit that you can eat or } \\
\text { make into wine? }\end{array}$ & grape & $100 \%$ \\
\hline
\end{tabular}

\subsection{Pengujian pendekatan User}

User Acceptance Test (UAT) atau Uji Penerimaan Pengguna adalah suatu proses pengujian oleh pengguna yang dimaksudkan untuk menghasilkan dokumen yang dijadikan bukti bahwa software yang telah dikembangkan telah dapat diterima oleh pengguna, apabila hasil pengujian sudah bisa dianggap memenuhi kebutuhan dari pengguna.

Proses UAT didasarkan pada dokumen requirement yang disepakati bersama. Dokumen requirement adalah dokumen yang berisi lingkup pekerjaan software yang harus dikembangkan, dengan demikian maka dokumen ini semestinya menjadi acuan untuk pengujian. Dalam hal ini dilakukan ke 25 rekan kantor yang menguji penyediaan layanan ini.

Pada penelitian ini, dokumen UAT dapat dijelaskan pada tabel berikut, menggunakan google form:

Tabel 2 Dokumen UAT

\begin{tabular}{|c|l|c|c|}
\hline Nomor & \multicolumn{1}{|c|}{ Pertanyaan } & Validasi & Persentase \\
\hline 1 & $\begin{array}{l}\text { Apakah tampilan menu awal } \\
\text { sudah user friendly? }\end{array}$ & Terpenuhi & $48 \%$ \\
\hline 2 & $\begin{array}{l}\text { Apakah informasi penggunaan } \\
\text { aplikasi sudah lengkap? }\end{array}$ & Terpenuhi & $56 \%$ \\
\hline 3 & $\begin{array}{l}\text { Apakah Ukuran Tulisan di } \\
\text { Aplikasi dapat terlihat dengan } \\
\text { jelas? }\end{array}$ & Terpenuhi & $64 \%$ \\
\hline 4 & $\begin{array}{l}\text { Apakah dengan aplikasi ini } \\
\text { mempermudah seorang pengguna } \\
\text { belajar Bahasa Inggris melalui } \\
\text { permainan Tebak Kata di aplikasi } \\
\text { ini? }\end{array}$ & Terpenuhi & $44 \%$ \\
\hline 5 & $\begin{array}{l}\text { Apakah Aplikasi dapat diakses } \\
\text { mudah dari Smartphone? }\end{array}$ & Terpenuhi & $52 \%$ \\
\hline
\end{tabular}

Data berupa grafik secara lengkap, dapat dijelaskan sebagai berikut: 
1. Pertanyaan pertama

25 responses

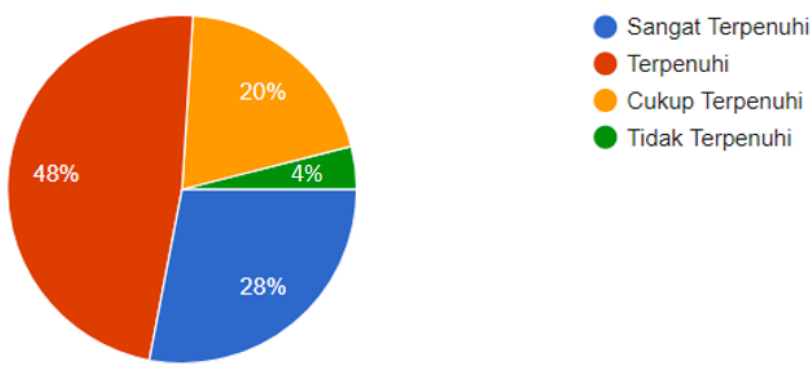

Gambar 9 pertanyaan pertama

Dari pertanyaan pertama, sebagian besar dengan persentase $48 \%$ memilih terpenuhi. Kemudian $28 \%$ sangat terpenuhi, 20\% cukup terpenuhi, 14\% tidak terpenuhi. Ada yang memilih tidak terpenuhi karena tampilan masih bawaan android studio.

2. Pertanyaan kedua

25 responses

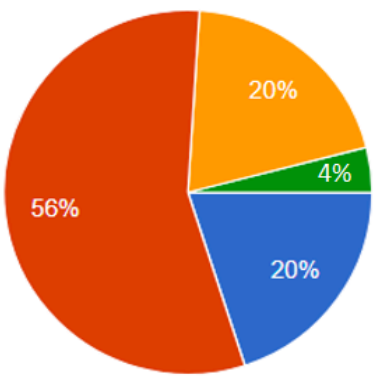

Sangat Terpenuhi

Terpenuhi

Cukup Terpenuhi

Tidak Terpenuhi

Gambar 10 pertanyaan kedua

Dari pertanyaan kedua, sebagian besar dengan persentase $56 \%$ memilih terpenuhi. Kemudian $20 \%$ sangat terpenuhi, $20 \%$ cukup terpenuhi, 4\% tidak terpenuhi. Ada yang memilih tidak terpenuhi karena informasi penggunaan tidak lengkap.

3. Pertanyaan ketiga

25 responses

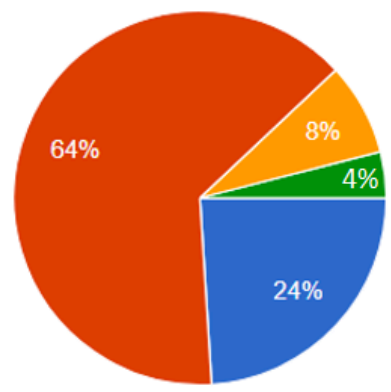

Sangat Terpenuhi

Terpenuhi

Cukup Terpenuhi

Tidak Terpenuhi

Gambar 11 pertanyaan ketiga 
Dari pertanyaan ketiga, sebagian besar dengan persentase $64 \%$ memilih terpenuhi. Kemudian $24 \%$ sangat terpenuhi, 8\% cukup terpenuhi, 4\% tidak terpenuhi. Ada yang memilih tidak terpenuhi karena ukuran tulisan masih terlihat kecil.

4. Pertanyaan keempat

25 responses

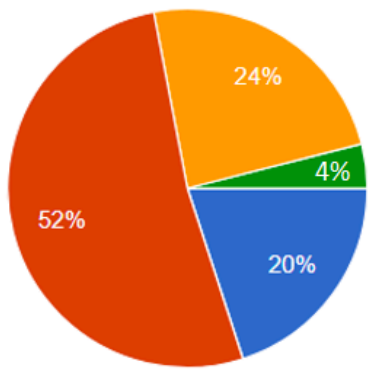

Sangat Terpenuhi

Terpenuhi

Cukup Terpenuhi

Tidak Terpenuhi

Gambar 12 pertanyaan keempat

Dari pertanyaan keempat, sebagian besar dengan persentase 52\% memilih terpenuhi. Kemudian $24 \%$ sangat terpenuhi, 20\% cukup terpenuhi, 4\% tidak terpenuhi. Ada yang memilih tidak terpenuhi karena masih menggunakaan internet untuk memainkannya.

\section{Pertanyaan kelima}

25 responses

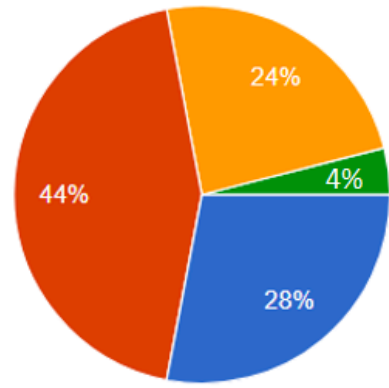

Tidak Terpenuhi

Gambar 13 pertanyaan kelima

Dari pertanyaan kelima, sebagian besar dengan persentase $44 \%$ memilih terpenuhi. Kemudian $28 \%$ sangat terpenuhi, $24 \%$ cukup terpenuhi, $4 \%$ tidak terpenuhi. Ada yang memilih tidak terpenuhi karena masih tulisan tidak dalam bentuk gambar dalam menjawab pertanyaan.

\section{KESIMPULAN}

Kesimpulan untuk menjawab rumusan permasalahan adalah bagaimana proses web crawler terhadap aplikasi permainan tebak kata, dan persentase keberhasilan dalam mengambil data yang disimpan di website yang sudah ada. Kedua, bagaimana aplikasi permainan tebak kata ini mempunyai antar muka yang mudah dipahami dan digunakan oleh pengguna. Dapat disimpulkan dari pengujian dengan web crawler yang dilakukan, terdapat percobaan sudah dilakukan, hasilnya dapat menarik data dengan mudah dengan persentase $100 \%$. Sedangkan 
untuk menjawab rumusan masalah yang kedua, dari hasil pengujian pendekatan terhadap pengguna dapat disimpulkan pembelajaran Bahasa Inggris dengan web crawler ini paling banyak terpilih adalah terpenuhi untuk digunakan.

\section{UCAPAN TERIMA KASIH}

Ucapan terima kasih kepada Lembaga Penelitian dan Pengabdian Masyarakat (LPPM) Universitas Mercu Buana Jakarta dengan nomor kontrak 02-5/205/B-SPK/XII/2017 sebagai sumber pendanaan yang telah memberikan fasilitas dan dukungan dalam pelaksanaan riset ini.

\section{DAFTAR PUSTAKA}

[1] Hastuti, dan Oswari, 2012, Metode Pembelajaran Bahasa Inggris Mandiri dengan Free Virtual Online Course, Jurnal Universitas Gunadarma Vol. 6 No. 11, Jakarta..

[2] Wahyuni, T., Marli, S., dan Sabri, T. 2014. Peningkatan Motivasi Belajar Siswa dengan Menggunakan Model Kooperatif Teknik Tebak Kata di Sekolah Dasar, Jurnal Pendidikan dan Pembelajaran Vol. 3 No. 11, Pontianak.

[3] Pavalam, Raja, K., Jawahar, M., dan Akorli, F,. 2012. Web Crawler in Mobile Systems, International Journal of Machine Learning and Computing, Vol. 2 No.4, Rwanda..

[4] Shkapenyuk, dan Suel. 2002. Design and Implementation of a High-Performance Distributed Web Crawler, International Conference on Data Engineering (ICDE), New York.

[5] Socialcubix. 2014. Mobile App Development Life Cycle. Diambil pada tanggal 11 November 2017 dari http://www.socialcubix.com/blog/mobile-app-development-lifecycle

[6] Sandiwarno, S. 2016. Perancangan Model E-Learning berbasis Collaborative Video Converence Learning guna mendapatkan Hasil Pembelajaran yang Efektif dan Efesien. Jurnal Ilmiah FIFO. Volume VIII/No. 2/November/2016.

[7] Ferianti, F., dan Hamzah, A. 2017. Model Pembelajaran Cooperative Learning Tipe Tebak Kata Terhadap Hasil Belajar Siswa Mata Pelajaran Bahasa Arab di MIN Kemu OKU Selatan. Jurnal Ilmiah PGMI. Volume 3, Nomor 2, Desember 2017

[8] Dhika, V.P, Lufri dan Des. 2017. Pengembangan Multimedia Interaktif Bermuatan Games Tebak Kata (MI-GTK) pada Materi Sistem Ekskresi Manusia untuk Peserta Didik Kelas XI SMA. Journal Biosains Volume 1 Nomor 22017

[9] Mokhtar, A., A. 2012. Guessing Word Meaning from Context Has Its Limit: Why?. International Journal of Linguistics. ISSN 1948-5425. Vol. 4, No. 2

[10] Salehi, M., dan Torki, R. 2017. The Effect of Using Cross-Word, Textual Guess and Wonder-Word on the Lexical Development of Iranian Students. International Journal of English Language \& Translation Studies. 5(4). 181-190. 